This is a postprint version of the following published document:

Venegas, M.; Vega, M.; García-Hernando, N. (2016). Parametric study of operating and design variables on the performance of a membrane-based absorber. Applied Thermal Engineering, v. 98, pp. 409-419.

DOI: $10.1016 / j$.applthermaleng.2015.12.074

(C) Elsevier 2016

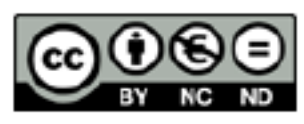

This work is licensed under a Creative Commons Attribution-NonCommercialNoDerivatives 4.0 International License. 


\title{
Parametric study of operating and design variables on the performance of a membrane-based absorber
}

\author{
M. Venegas a,b,c,*, M. de Vega ${ }^{\mathrm{a}, \mathrm{c}}$, N. García-Hernando ${ }^{\mathrm{a}, \mathrm{c}}$
}

\begin{abstract}
a ISE Research Group, Department of Thermal and Fluids Engineering, Universidad Carlos III de Madrid, Avda. Universidad 30, Leganés, Madrid 28911, Spain
${ }^{\mathrm{b}}$ GTADS Research Group, Department of Thermal and Fluids Engineering, Universidad Carlos III de Madrid, Avda. Universidad 30, Leganés, Madrid 28911,

Spain

c Associated Research Unit CSIC-Universidad Carlos III de Madrid, Spain
\end{abstract}

H I G H L I G H T S

- A microchannel $\mathrm{H}_{2} \mathrm{O}-\mathrm{LiBr}$ absorber using a microporous membrane is simulated.

- Sensitivity of cooling capacity/absorber volume to various parameters is evaluated.

- Parameters to be optimised at the design stage of the absorber are identified.

- Porosity, pore diameter, solution channels depth and membrane thickness are crucial.

- Vapour pressure and solution inlet temperature and concentration should be optimised.

Keywords:

Absorption refrigeration

Membrane

Absorber

Water-lithium bromide

Rectangular microchannel

Parametric study

\section{A B S T R A C T}

A plate-and-frame microchannel $\mathrm{H}_{2} \mathrm{O}-\mathrm{LiBr}$ absorber using a microporous membrane as contactor between the vapour and the solution is simulated. The heat and mass transfer equations, describing the absorp-tion of the vapour phase into the solution, are solved for different membrane properties and for variable design and operating conditions. The parametric study evaluates the sensitivity of the ratio between the cooling capacity of the chiller and the absorber volume $(r q V)$ to changes in the following parameters: width and height of the solution and cooling water channels; concentration,

temperature and mass flow rate of the solution; temperature and mass flow rate of the cooling water; porosity, pore diameter, thickness and thermal conductivity of the membrane; thickness and

thermal conductivity of the interface wall between the solution and the cooling water; and temperature, pressure and mass flow rate of the vapour. At the design stage of the membrane absorber, the parameters that can be optimised to maximise $r q V$ are porosity, pore diameter, solution channels depth and membrane thickness. The thickness of the in-terface wall between the

solution and the cooling water, as well as the solution channels width should be also taken into account. For a good performance during the operation of the absorber, special care should be taken to select the adequate vapour pressure and solution inlet temperature and concentration.

\section{Introduction}

Absorption cooling technology can contribute to the reduction in $\mathrm{CO}_{2}$ emissions particularly in the case of the $\mathrm{H}_{2} \mathrm{O}-\mathrm{LiBr}$ solution since this system can be fed with low heat temperature sources such as solar panels. However, its generalisation remains limited for small cooling power applications. One of the main constraints for the development of small air conditioning units using $\mathrm{H}_{2} \mathrm{O}-\mathrm{LiBr}$ absorption chillers is the size required, which is still, by far, larger than the size of the conventional mechanical compression systems: volume to refrigeration power ratio in single effect absorption chillers is in the

\footnotetext{
* Corresponding author. Tel.: +34 916248776; fax: +34 916249430.

E-mail address: mvenegas@ing.uc3m.es (M. Venegas).
}

order of $0.04 \mathrm{~m}^{3} / \mathrm{kW}$, without considering the volume occupied by the cooling system, for refrigeration capacities between 10 and $30 \mathrm{~kW}$, whereas mechanical compressor systems can have a ratio equal to $0.02 \mathrm{~m}^{3} / \mathrm{kW}$ for the same range of refrigeration capacities (García-Hernando et al. [1]). In order to increase the cooling capacity to volume ratio in absorption systems new absorber designs have been investigated based in changes in the vapour-solution interface configuration by means of bubbles, sprays and droplets, liquid jets and sheets, etc. The use of compact heat exchangers has also been studied (Venegas et al. [2], de Vega et al. [3]). At present a promising new technology is considered, consisting in the use of membrane contactors in microchannel heat exchangers.

Hydrophobic microporous membranes have already been used as contactors in chemical absorption processes for $\mathrm{CO}_{2}, \mathrm{H}_{2} \mathrm{~S}$ and $\mathrm{SO}_{2}$ removal from flue gases or membrane distillation. Despite the 
addition of an extra mass transfer resistance caused by the membrane, microporous fibre membrane contactors present the advantage of a compact modular structure to provide larger interfacial area per unit volume, independent control of vapour and liquid flow rates and easier scale up. In membrane refrigeration absorbers, the microporous polymeric membrane can be used at the solutionrefrigerant vapour interface: surface tension prevents the solution from entering the holes, while the vapour diffuses to the solution surface through the pores. In this way, in the absorber, the gaseous fluid (typically ammonia or water vapour) passes the membrane and it is absorbed by the solution $\left(\mathrm{NH}_{3}-\mathrm{H}_{2} \mathrm{O}\right.$ or $\mathrm{H}_{2} \mathrm{O}-$ $\mathrm{LiBr}$ respectively), flowing inside constrained flow passages. The vapour pressure difference across the membrane is the driving force for vapour mass transfer. The knowledge of the processes associated with the heat and mass transfer in absorbers using membrane technology in microchannel heat exchangers is of primal importance to improve the design and the potential for further size reductions.

We will focus our attention in water-lithium bromide systems. Theoretical studies of Ali and Schwerdt [4,5] using the $\mathrm{H}_{2} \mathrm{O}-\mathrm{LiBr}$ solution, specified the characteristics of an appropriate membrane to be used in the absorber. High thickness of the membrane, leads to higher resistance to mass transfer while the mechanical stability improves. The authors concluded that the layer thickness should be up to $60 \mu \mathrm{m}$ as a compromise between both constraints. In a subsequent study, Ali and Schwerdt [6] concluded that a large pore diameter combined with a porosity value of 0.8 leads to an almost doubled water vapour flux through the membrane compared to a 0.5 porosity value. With the aim of achieving higher vapour fluxes and taking into account the strength needed for the secure fixation of the membrane inside the absorber, the authors recommended that an appropriate membrane should have a porosity ranging between 0.7 and 0.8 .

Isfahani and Moghaddam [7] tested an absorber using a superhydrophobic nanofibrous membrane with nominal pore size of $1 \mu \mathrm{m}$ and $80 \%$ porosity. They obtained an absorption rate of about $0.006 \mathrm{~kg} / \mathrm{m}^{2} \mathrm{~s}$, using channels of $100 \mu \mathrm{m}$ thickness and a flow velocity of $5 \mathrm{~mm} / \mathrm{s}$. Isfahani et al. [8] presented permeability studies of highly porous nanofibrous membranes concluding that membranes with a pore size greater than about $1 \mu \mathrm{m}$ are valid for their application in the absorber.

Yu et al. [9] numerically investigated the performance of a membrane-based absorber using the $\mathrm{H}_{2} \mathrm{O}$ - $\mathrm{LiBr}$ solution obtaining higher absorption rates compared to conventional absorbers. They showed that the reduction in film thickness from 150 to $50 \mu \mathrm{m}$, and high solution velocities provided large increases in the absorption rate. Bigham et al. [10] showed that mass transport in the microfilm solution could be improved by the implementation of microscale features on the flow channel surface. Recently a review of membrane contactors applied in absorption refrigeration systems has been presented by Asfand and Bourouis [11].

Taking into account the literature review, in order to reduce the absorber volume in water-lithium bromide systems, detailed studies about the role of the relevant design and operating parameters in the absorption process are still necessary. In a previous paper [12], a model to predict the absorption rate, the heat and mass transfer coefficients, as well as the properties of the working fluids along the absorption channels of a membrane absorber was developed. This model was validated using experimental data of Isfahani and Moghaddam [7]. In that paper, the influence of the solution and cooling water channels aspect ratios on the performance of the absorber was also evaluated. In the present investigation, the model developed in [12] has been modified to take into account the different regimes occurring for the varying conditions of the possible configurations in a microchannel absorber. The parametric study is performed to evaluate the relative and absolute influence of geometrical, physical properties and operating variables on the ratio

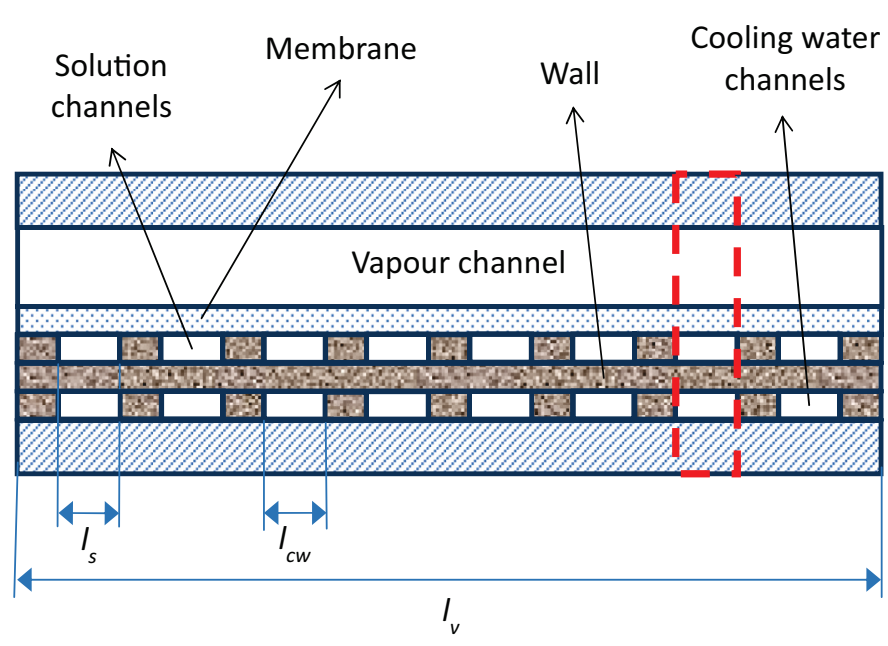

Fig. 1. Cross section of the plate and frame membrane-based absorber.

between the cooling power of the chiller equipped with the simulated absorber and the volume of this absorber. Results obtained can be used to optimise the design and operation of membrane absorbers, with the principal aim of reducing the chiller size.

\section{Absorber configuration}

The configuration considered for the absorber in the present study is shown in Fig. 1. It is a plate-and-frame membrane module, consisting of a vapour channel, the porous hydrophobic membrane that separates the vapour from the solution and the cooling water channels separated by a wall from the solution. Water-lithium bromide solution is used. In this configuration one surface of the membrane is in direct contact with the vapour and the other side is in contact with the solution. Due to the hydrophobicity of the membrane, the aqueous solution cannot enter the pores. Vapour is transported through the membrane pores and it is absorbed on the vapour-liquid interface at the solution side of the membrane. The difference between partial vapour pressures is the effective driving force for vapour transport. The heat of absorption is to be removed from the vapour-liquid interface in the solution side. This is the reason why the cooling channels are also considered.

The membrane resistance to the vapour transport depends on the size and tortuosity of the membrane pores, and on the porosity and thickness of the membrane. The selection of a suitable membrane is crucial because the overall mass transfer of a contactor can be significantly affected by the membrane properties. The effects of these parameters on the absorption performance are compared in the parametric study presented in the following. The boundary layer mass transfer coefficient in the solution depends on the properties of the solution and on the hydrodynamic conditions of the system. These conditions are also varied and their influence in the absorber performance is presented.

The base case geometry and operating conditions of the absorber are given in Table 1 . These could correspond to the absorber working in a chiller with the pressures, temperatures and concentrations in the generator and the evaporator as shown in Table 2, considering that the solution temperature at the outlet of the absorber is equal to the condensation temperature.

\section{Heat and mass transfer model}

Our model is based in the dusty-gas model [13] (for the vapour mass transfer through the membrane) and the film theory: the heat and mass transfer equations are described in terms of the 
Table 1

Base case data considered for the parametric study, corresponding to the schemes of the absorber represented in Figs. 1 and 2.

\begin{tabular}{lc}
\hline Parameter & Value \\
\hline Porosity, $\varepsilon$ & 0.8 \\
Pore diameter, $d_{p}(\mu \mathrm{m})$ & 1 \\
Membrane thermal conductivity, $k_{m}(\mathrm{~W} / \mathrm{mK})$ & 0.22 \\
Membrane thickness, $e_{m}(\mu \mathrm{m})$ & 60 \\
Total cooling water mass flow rate, $\dot{m}_{c w, T}(\mathrm{~g} / \mathrm{s})$ & 0.5 \\
Total solution mass flow rate at the inlet, $\dot{m}_{s, T}(\mathrm{~g} / \mathrm{s})$ & 1 \\
Wall thermal conductivity, $k_{w}(\mathrm{~W} / \mathrm{mK})$ & 10 \\
Wall thickness, $e_{w}(\mathrm{~mm})$ & 2.7 \\
Cooling water inlet temperature, $T_{c w}\left({ }^{\circ} \mathrm{C}\right)$ & 27 \\
Solution inlet temperature, $T_{s}\left({ }^{\circ} \mathrm{C}\right)$ & 32 \\
LiBr mass fraction at the inlet, $x$ & 0.6 \\
Vapour mass flow rate at the inlet, $\dot{m}_{v}(\mathrm{~g} / \mathrm{s})$ & 0.0032 \\
Vapour inlet superheating, $\Delta T\left({ }^{\circ} \mathrm{C}\right)$ & 0.03 \\
Vapour pressure, $P_{v}(\mathrm{kPa})$ & 1 \\
Solution channel width, $l_{s}(\mathrm{~mm})$ & 1.5 \\
Solution channel height, $e_{s}(\mathrm{~mm})$ & 0.15 \\
Cooling water channel width, $l_{c w}(\mathrm{~mm})$ & 1.5 \\
Cooling water channel height, $e_{c w}(\mathrm{~mm})$ & 0.15 \\
Vapour channel height, $e_{v}(\mathrm{~mm})$ & 5 \\
Solution channel centre-to-centre distance, $w_{s}(\mathrm{~mm})$ & 1.6 \\
Cooling water channel centre-to-centre distance, $w_{c w}(\mathrm{~mm})$ & 1.6 \\
Vapour channel aspect ratio, $\alpha \alpha_{v}$ & 4 \\
Length of channels, $L(\mathrm{~mm})$ & 50 \\
Discretisation length, $d z(\mathrm{~mm})$ & 0.22 \\
\hline
\end{tabular}

Table 2

Operating data of the absorption chiller.

\begin{tabular}{lrlrll}
\hline Absorber & \multicolumn{3}{c}{ Generator } & \multicolumn{3}{c}{ Evaporator } \\
\hline$T_{s, i}\left({ }^{\circ} \mathrm{C}\right)$ & 30 & $T_{s, o}\left({ }^{\circ} \mathrm{C}\right)$ & 75.7 & $T_{e}\left({ }^{\circ} \mathrm{C}\right)$ & 7 \\
$P_{a}(\mathrm{kPa})$ & 1 & $P_{g}(\mathrm{kPa})$ & 4.7 & $P_{e}(\mathrm{kPa})$ & 1 \\
$x_{s, i}(\%)$ & 60 & $x_{s, i}(\%)$ & 58.6 & $\dot{m}_{v}(\mathrm{~g} / \mathrm{s})$ & $2.3 \cdot 10^{-3}$ \\
$\dot{m}_{s, i}(\mathrm{~g} / \mathrm{s})$ & 0.1 & & & & \\
\hline
\end{tabular}

corresponding mass and heat transfer coefficients. These equations are combined with the global energy and mass balances to predict the performance of the absorber.

The absorber is discretised in " $j$ " differential elements as shown in Fig. 2. Using the inlet conditions, the variables at the outlet of the element " $j$ " are calculated.

\subsection{Energy and mass balances}

A global energy balance, comprising the heat generated by the absorption of a $\dot{m}_{v a}$ mass flow rate of vapour, in the differential element $j$ can be written as:

$\left(\dot{m}_{v a} i_{l v}\right)^{j}=q_{s}^{j}+q_{v}^{j}+q_{c w}^{j}$

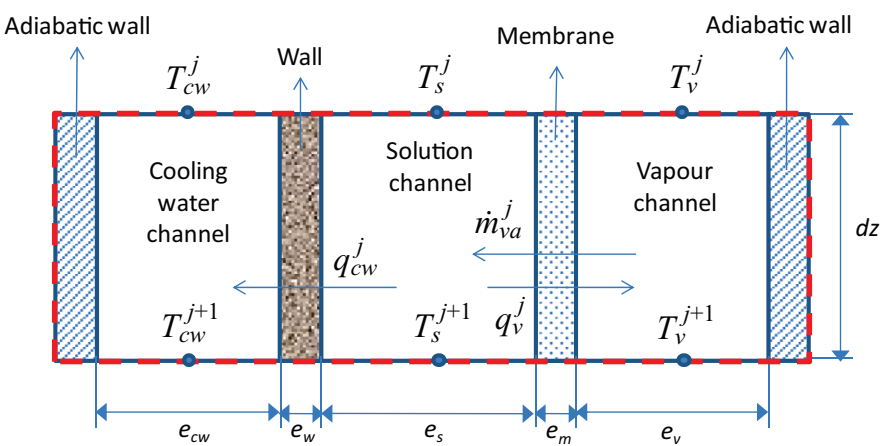

Right terms in Eq. (1) are related to the heat transferred to the solution, vapour and cooling water respectively. These can be calculated, for parallel flow, as:

$q_{s}^{j}=(\dot{m} \cdot i)_{s}^{j+1}-(\dot{m} \cdot i)_{s}^{j}$

$q_{v}^{j}=(\dot{m} \cdot i)_{v}^{j+1}-(\dot{m} \cdot i)_{v}^{j}$

$q_{c w}^{j}=\dot{m}_{c w}\left(i_{c w}^{j+1}-i_{c w}^{j}\right)=\dot{m}_{c w} C p_{c w}^{j}\left(T_{c w}^{j+1}-T_{c w}^{j}\right)$

Mass rate balances for solution and vapour give the mass flow rates in the differential element $j+1$ :

$\dot{m}_{s}^{j+1}=\dot{m}_{s}^{j}+\dot{m}_{v a}^{j}$

$\dot{m}_{v}^{j+1}=\dot{m}_{v}^{j}-\dot{m}_{v a}^{j}$

Mass fraction of lithium bromide in the solution is calculated by:

$x^{j+1}=x^{j} \frac{\dot{m}_{s}^{j}}{\dot{m}_{s}^{j+1}}$

Left term in Eq. (1) corresponds to the thermal power released during absorption of the vapour flow rate $\dot{m}_{v a}$ into the solution. This mass flow rate is calculated as:

$\dot{m}_{v a}^{j}=J^{j} \cdot A$

where $A$ is the heat and mass transfer area:

$A=l_{s} \cdot d z$

and $J$ is the absorption rate:

$J^{j}=\frac{P_{v}-P_{s}^{j}}{R_{o v}^{j}}$

$P_{v}$ and $P_{s}$ are the bulk vapour pressure and the water vapour partial pressure corresponding to the bulk solution concentration $(x)$ and temperature $\left(T_{s}\right)$, according to Ali [14]. $R_{o v}^{j}$ is the overall mass transfer resistance.

\subsection{Resistance-in-series model for the mass transfer process}

The vapour mass transport can be described as a two step process (Fig. 3): (1) transport through the membrane, (2) transport through the concentration boundary layer on the solution side. It can be seen that the vapour works with two resistances in series, i.e. membrane $\left(R_{m}\right)$ and liquid phase boundary layer $\left(R_{s}\right)$. Hence, a resistancein-series model can express the total resistance, $R_{o v}$, defined as the reciprocal of the overall mass transfer coefficient, $K_{o v}$ :

$R_{o v}^{j}=R_{m}^{j}+R_{s}^{j}=\frac{1}{K_{o v}^{j}}$

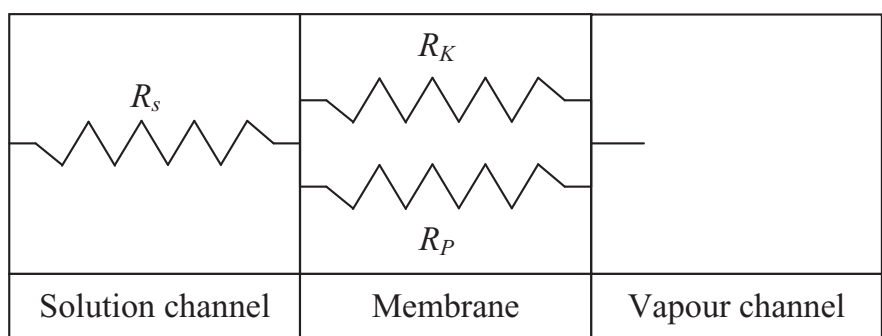

Fig. 3. Mass transfer resistances in the absorber

Fig. 2. Differential element of the absorber. 
Depending on the value of the Knudsen number, $K n$ (defined as the ratio of the molecule mean free path to pore characteristic diameter), different mechanisms by which vapour may be transported through the membrane are established: (i) Knudsen diffusion, (ii) viscous flux (Poiseuille flow) and (iii) transition flow. The dustygas model assumes that the Knudsen diffusion resistance $R_{K}$ is in parallel with the Poiseuille flow resistance $R_{P}$, as shown in Fig. 3, obtaining:

$\frac{1}{R_{m}^{j}}=\frac{1}{R_{K}^{j}}+\frac{1}{R_{P}^{j}}=K_{m}^{j}$

For each of these regimes, the transport resistance can be calculated as follows:

1. When Knudsen is large $(K n \geq 10)$, collisions between molecules and pore wall are dominant and the gas transport takes place via Knudsen flow, for which the mass transfer coefficient can be calculated as:

$K_{m}=\frac{M}{e_{m}}\left(\frac{D_{e}^{K}}{R_{u} T_{m}}\right)$

where:

$D_{e}^{K}=\frac{\varepsilon d_{p}}{3 \tau}\left(\frac{8 R_{u} T_{m}}{\pi M}\right)^{0.5}$

2. When the Knudsen number is small $(K n<0.01)$, collisions between gas molecules dominate and viscous or Poiseuille flow occurs, resulting in rapid convective transport, and the mass transfer coefficient can be evaluated as:

$K_{m}=\frac{M}{e_{m}}\left(\frac{P_{m} B_{o}}{R_{u} T_{m} \mu_{v}}\right)$

where $B_{0}=\frac{\varepsilon d_{p}^{2}}{32 \tau}$

3. In between, the flow can be considered a transition flow, and the mass transport coefficient according to the resistance analogy can be written as:

$K_{m}=\frac{M}{e_{m}}\left(\frac{D_{e}^{K}}{R_{u} T_{m}}+\frac{P_{m} B_{0}}{R_{u} T_{m} \mu_{v}}\right)$

In Eqs. (13) and (15), $M$ is the molecular weight of water, $e_{m}$ is the membrane thickness and $R_{u}$ is the universal gases constant. In Eq. (15), $\mu_{v}$ refers to the vapour viscosity. In Eqs. (14) and (15), $\varepsilon$ and $\tau$ are the porosity and tortuosity of the membrane, respectively. Tortuosity of the membrane is calculated as a function of the membrane porosity, according to Iversen et al. [15]:

$\tau=\frac{(2-\varepsilon)^{2}}{\varepsilon}$

For the current parametric study, Knudsen number ranges between 8 and 46. Consequently, transitional regime or free molecular flow occurs through the membrane along the absorber.

Resistance to mass transfer inside the bulk solution $R_{S}$ can be calculated according to Ali and Schwerdt [5], as:

$R_{s}^{j}=\frac{P_{\text {sat }}^{j}}{\rho_{w a t e r}^{j} K_{s}^{j}}$

where $P_{\text {sat }}$ is the saturated water pressure corresponding to the bulk solution temperature, $\rho_{\text {water }}$ is the liquid water density and $K_{s}$ is the mass transfer coefficient between the solution-vapour interface and the bulk aqueous solution. Mass transfer coefficients are generally obtained using correlations for the Sherwood number, which contains the mass transfer coefficient, as a function of the Reynolds number and Schmidt number. Nevertheless, a suitable correlation for mass transfer in microchannels has not been found in the open literature. For this reason, the mass transfer coefficient of the solution is calculated using mass and heat transfer analogy, by means of correlations previously described by Lee and Garimella [16] for the thermal entrance region and Shah and London [17] for fully developed flow.

\subsection{Heat transfer}

The present model considers that heat is transferred from the bulk solution channel (where absorption takes place) to both cooling water and vapour channels. The heat transfer can be described by the corresponding convection and conduction resistances in series. The following relations apply:

$q_{c w}^{j}=U_{s_{-} c w}^{j} A\left(T_{s}^{j}-T_{c w}^{j}\right)$

$q_{v}^{j}=U_{S_{-} v}^{j} A\left(T_{s}^{j}-T_{v}^{j}\right)$

where the global heat transfer coefficients in Eqs. (19) and (20) are calculated as:

$\frac{1}{U_{s_{-} c w}^{j}}=\frac{1}{h_{c w}^{j}}+\frac{e_{w}}{k_{w}^{j}}+\frac{1}{h_{s, c w *}^{j}}$

$\frac{1}{U_{s_{-} v}^{j}}=\frac{1}{h_{v}^{j}}+\frac{e_{m}}{k_{m, a v e}^{j}}+\frac{1}{h_{s, v *}^{j}}$

Two different models have been considered to evaluate the average thermal conductivity of the membrane $k_{m \text {,ave }}$ :

- The classical parallel model, as given in Martínez and RodríguezMaroto [18]:

$k_{m, a v e}=\varepsilon k_{v}+(1-\varepsilon) k_{m}$

- The Maxwell's model (Type I), described by García-Payo and Izquierdo-Gil [19]. Based on their experimental study using PVDF and PTFE membranes, they recommend the following expression for highly porous membranes:

$k_{m, a v e}=k_{v}\left(\frac{1+2 \beta \varphi}{1-\beta \varphi}\right)$

where:

$\beta=\frac{k_{m}-k_{v}}{k_{m}+2 k_{v}}$

$\varphi=1-\varepsilon$

In Eqs. (23)-(25), $k_{v}$ is the thermal conductivity of the vapour inside the membrane pores, while $k_{m}$ is the thermal conductivity of the membrane solid material. Both correlations were implemented in the present model of membrane absorber and no significant change was observed in the results. This is a consequence of the low relative contribution of the membrane thermal conductivity to the heat and mass transfer processes in the absorber, as it will be shown in the last section of this paper.

In Eqs. (21) and (22), the convection heat transfer coefficients along the solution, cooling water and vapour channels have been 
calculated taking into account the existence of the thermal entrance region and the fully developed flow. Correlations to be used were selected also considering the dimensions of the channels.

In the case of the solution and cooling water channels, equations of Lee and Garimella [16] for microchannels were used to estimate the length of the thermal entrance region and the convection heat transfer coefficients here. This correlation has the advantage, with respect to others available in the open literature, of allowing the estimation of the heat transfer coefficient as a function of the position along the channel. Also, it covers a broad range of aspect ratios and hydraulic diameters. The Nusselt number in the entry region is calculated as:

$N u_{t h}=\frac{1}{C_{1}\left(z^{*}\right)^{C_{2}}+C_{3}}+C_{4}, \quad$ for $1 \leq \alpha \leq 10, \quad z^{*}<z_{t h}^{*}$

The dimensionless length of the thermal entrance region $z_{\text {th }}^{*}$ and equations for calculating $C_{1}-C_{4}$ can be found in Lee and Garimella [16].

Convection heat transfer coefficients along the microchannels for the fully developed flow were obtained using the correlation developed by Shah and London [17]. This correlation is valid for rectangular channels:

$N u=8.235\left(1-\frac{2.0421}{\alpha}+\frac{3.0853}{\alpha^{2}}-\frac{2.4765}{\alpha^{3}}+\frac{1.0578}{\alpha^{4}}-\frac{0.1861}{\alpha^{5}}\right)$

In the case of the solution channel, the effect of mass transfer on heat transfer was taken into account using a modified heat transfer coefficient. Coefficients obtained using Eqs. (27) and (28) were corrected, multiplying them by the Ackermann factor (Taylor and Krishna [20]):

$\Xi=\frac{\Phi}{e^{\Phi}-1}$

where the heat transfer rate factor $\Phi$ is defined as:

$\Phi=J \cdot C p_{v} \cdot e_{s} / k_{v}$
The modified convection coefficient for heat transfer from the solution to the cooling water channel is incremented because mass transfer is taking place in the same direction of heat transfer. In the case of heat transfer to the vapour channel the coefficient is reduced because the processes occur in opposite directions.

The vapour channel is a conventional rectangular channel with $D_{h, v}=8 \mathrm{~mm}$ and $\alpha_{v}=4$. In this case, the dimensionless thermal entry length, Nusselt number in this developing region and Nusselt number in the thermally developed flow are calculated using the correlations derived by Venegas et al. [12]. Correlations for the thermal entrance and fully developed flow regions are respectively:

$$
\begin{aligned}
& N u_{t h, v}=-3 \cdot 10^{-5}\left(z_{v}^{*}\right)^{2}+0.0307 z_{v}^{*}+5.2901 \\
& N u_{v}=-\frac{0.037}{\alpha_{v}^{2}}+\frac{0.7639}{\alpha_{v}}+2.8036
\end{aligned}
$$

The solution of the heat and mass transfer problem along the channels cannot be explicitly determined from Eqs. (1) to (32). For this reason, the above set of equations should be solved iteratively. They have been compiled in a computer code developed by the authors using Engineering Equation Solver software, EES ${ }^{\mathrm{TM}}$ (Klein [21]). Fig. 4 shows the flowchart used to implement the heat and mass transfer models.

Some thermodynamic and transport properties of the working fluids are calculated using correlations available in EES ${ }^{\mathrm{TM}}$. The thermodynamic properties of the water-lithium bromide solution are calculated using correlations developed by Patek and Klomfar [22]. EES $^{\mathrm{TM}}$ uses for water the correlation of Harr et al. [23]. The viscosity and thermal conductivity of the water-lithium bromide solution are computed using correlations provided by Lee et al. [24] and DiGuilio et al. [25], respectively. The transport properties of water are calculated using equations of the Electrical Research Association [26]. Newer correlations are available for the thermal conductivity and viscosity of water (Huber et al. [27,28]), but negligible differences are obtained between the use of these correlations or the ones in [26] for liquid water and vapour at typical operating conditions in the absorber. As no significant error is introduced

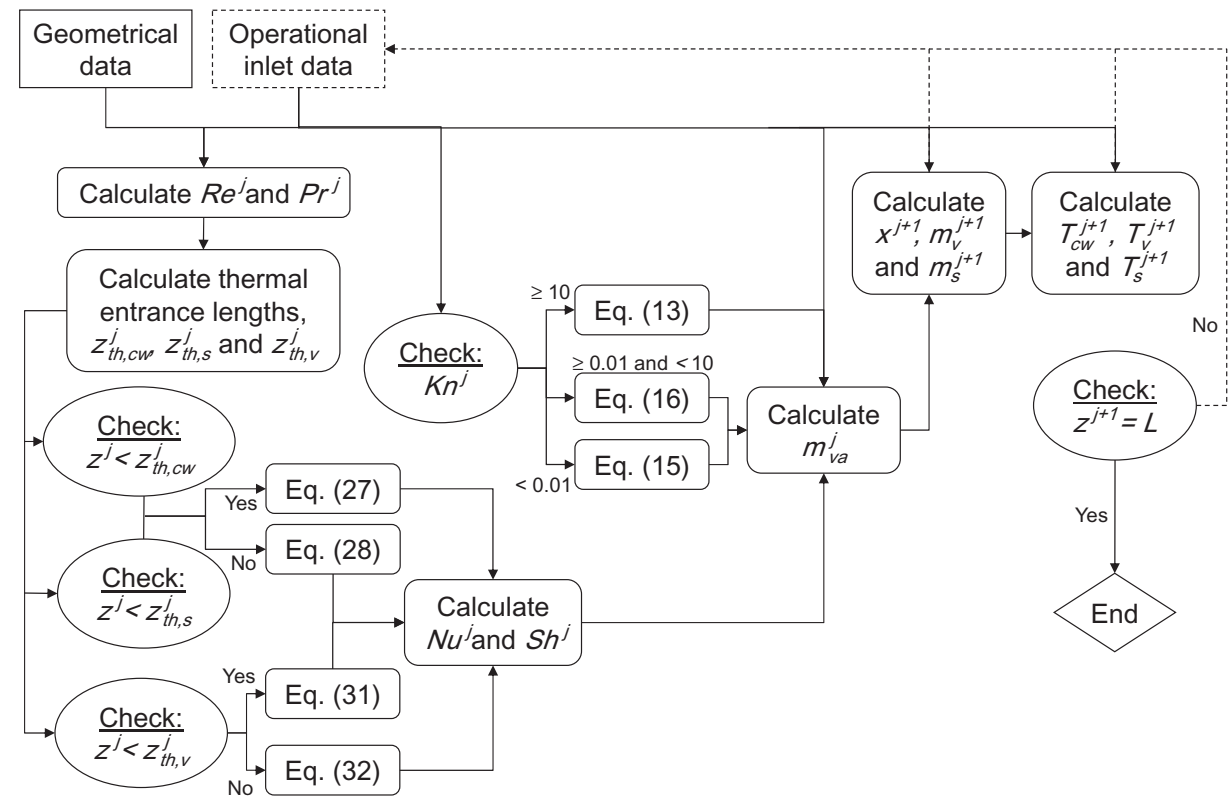

Fig. 4. Flowchart for simulating the heat and mass transfer process along the absorption channel. 
in the results using the correlation defined in EES ${ }^{\mathrm{TM}}$ for transport properties of water, this is the one employed in our model.

The following transport properties were not calculated with correlations available in $\mathrm{EES}^{\mathrm{TM}}$ :

- The diffusion coefficient of water in the water-lithium bromide solution has been calculated using the equation described by Mittermaier et al. [29].

- The thermal conductivity selected for the membrane in the base case was $0.22 \mathrm{~W} / \mathrm{mK}$, the same value used by Ali [14].

- The thermal conductivity of the metal wall was assumed to be $10 \mathrm{~W} / \mathrm{mK}$. This is a typical value for corrosion-resistant metals and alloys according to Chawla and Gupta [30].

\section{Results and discussion}

\subsection{Model validation}

Validation of the model has been performed comparing the absorption rate predicted with the experimental data reported by Isfahani and Moghaddam [7]. In the experimental case, the solution and cooling water channels measure 1 and $4 \mathrm{~mm}$ in width respectively. The solution channel of $0.16 \mathrm{~mm}$ height was used for the validation. The cooling water channel height was $0.4 \mathrm{~mm}$. An important issue is that the correlations used in the present model remain valid in all the cases.

Fig. 5 shows a comparison between the absorption rate predicted by the model, using the data of Isfahani and Moghaddam [7], and their experimental results. The figure shows the combined influence of the solution mass flow rate and the vapour pressure on the absorption rate. Experiments and simulation agree well. The almost similar trends show the good prediction of the model concerning the vapour pressure increase influence: the absorption rate increases because the vapour pressure potential rises. As observed, the increase of the solution mass flow rate also tends to boost the mass transfer.

The mean absolute error of the model predictions respect to all experimental data represented in Fig. 5 is $5.8 \%$. This low difference demonstrates the value of the model to perform a good prediction of the miniaturised membrane-based absorber performance. Also, it allows evaluating the influence of individual parameters on the absorption rate.

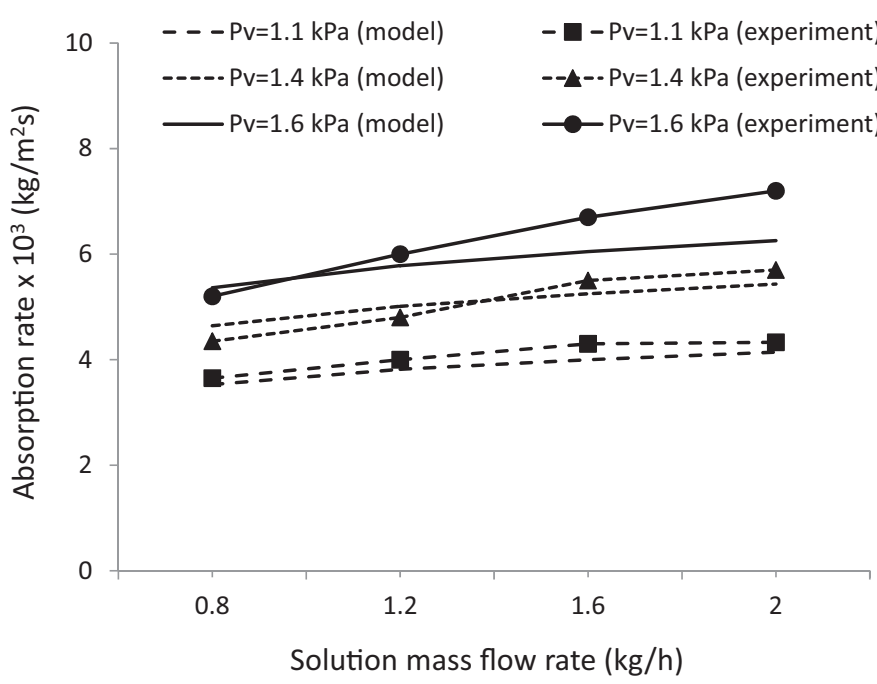

Fig. 5. Absorption rate as a function of the solution mass flow rate and the vapour pressure $\left(P_{v}\right)$. Comparison between model and experimental results of Isfahni and Moghaddam [7].

\subsection{Parametric study}

A base case has been considered for the simulation. Design data and operating variables corresponding to the base case are described in Table 1 . The dimensions and parameters in Table 1 were kept constant for all the cases of the parametric study unless otherwise stated. The changed parameters include membrane properties, microchannels characteristics, mass flow rates, concentration, pressure and temperatures of the working fluids. Table 3 provides the range covered by the parameters evaluated.

The parametric study is intended to minimise the absorber volume, with the final objective of reducing the size of absorption cooling chillers. The variable used to evaluate the absorber compactness is the ratio between the cooling power of the chiller equipped with it and the absorber volume, $r_{q v}$. The objective is maximising the value of $r_{q V}$.

$r_{q V}=q_{\text {chiller }} / V_{a}$

With the aim of providing general data about the absorber performance, Table 4 shows the solution temperature, saturation pressure and $\mathrm{LiBr}$ mass fraction at the outlet of the absorber, for typical operating conditions at the inlet. Fig. 6 shows the evolution of the same properties along the absorption channel, for the second case represented in Table 4 . The rest of operating and design data are identical to those described in Table 1.

Figs. 7-13 show the sensitivity of $r_{q v}$ to the different parameters analysed in the present study. Table 3 , as a summary, provides the maximum percentage change in $r_{q v}$, when each of the param-

Table 3

Range of the parameters considered and maximum percentage increment and decrease obtained in $r_{q V}$ respect to the base case.

\begin{tabular}{|c|c|c|c|}
\hline Parameter & Range & $\begin{array}{l}\text { Increment } \\
(\%)\end{array}$ & $\begin{array}{l}\text { Decrease } \\
(\%)\end{array}$ \\
\hline Porosity, $\varepsilon$ & $0.5-0.9$ & 18.17 & -58.13 \\
\hline Pore diameter, $d_{p}(\mu \mathrm{m})$ & $0.3-1.5$ & 18.97 & -51.89 \\
\hline $\begin{array}{l}\text { Membrane thermal conductivity, } \\
k_{m}(\mathrm{~W} / \mathrm{mK})\end{array}$ & $0.1-0.3$ & 0.01 & 0.00 \\
\hline Membrane thickness, $e_{m}(\mu \mathrm{m})$ & $50-210$ & 8.39 & -54.36 \\
\hline $\begin{array}{l}\text { Total cooling water mass flow rate, } \\
\dot{m}_{c w, T}(\mathrm{~g} / \mathrm{s})\end{array}$ & $0.4-1.6$ & 2.27 & -0.67 \\
\hline $\begin{array}{l}\text { Total solution mass flow rate at the } \\
\text { inlet, } \dot{m}_{s, T}(\mathrm{~g} / \mathrm{s})\end{array}$ & $0.4-1.6$ & 7.08 & -11.48 \\
\hline Wall thermal conductivity, $k_{w}(\mathrm{~W} / \mathrm{mK})$ & $8-24$ & 2.90 & -0.95 \\
\hline Wall thickness, $e_{w}(\mathrm{~mm})$ & $0.6-3$ & 35.58 & -3.63 \\
\hline $\begin{array}{l}\text { Cooling water inlet temperature, } \\
T_{c w}\left({ }^{\circ} \mathrm{C}\right)\end{array}$ & $20-32$ & 12.14 & -10.13 \\
\hline Solution inlet temperature, $T_{S}\left({ }^{\circ} \mathrm{C}\right)$ & $30-50$ & 8.04 & -77.42 \\
\hline $\mathrm{LiBr}$ mass fraction at the inlet, $x$ & $0.54-0.62$ & 10.73 & -63.75 \\
\hline $\begin{array}{l}\text { Vapour mass flow rate at the inlet, } \\
\dot{m}_{v}(\mathrm{~g} / \mathrm{s})\end{array}$ & $0.004-0.012$ & 0.05 & -0.04 \\
\hline Vapour inlet superheating, $\Delta T\left({ }^{\circ} \mathrm{C}\right)$ & $0-8$ & 0.01 & -0.82 \\
\hline Vapour pressure, $P_{v}(\mathrm{kPa})$ & $0.8-1.6$ & 85.1 & -29.15 \\
\hline Solution channel width, $l_{s}(\mathrm{~mm})$ & $0.15-1.5$ & 0.00 & -31.80 \\
\hline Solution channel height, $e_{S}(\mathrm{~mm})$ & $0.15-1.5$ & 0.00 & -66.88 \\
\hline Cooling water channel width, $l_{c w}(\mathrm{~mm})$ & $0.15-1.5$ & 0.00 & -0.19 \\
\hline Cooling water channel height, $e_{c w}(\mathrm{~mm})$ & $0.15-1.5$ & 0.00 & -17.34 \\
\hline
\end{tabular}

Table 4

Conditions at the outlet of the absorber for different operating data.

\begin{tabular}{lllllll}
\hline \multicolumn{2}{l}{ Inlet operating conditions } & & & \multicolumn{3}{l}{ Outlet conditions } \\
\cline { 1 - 2 }$T_{s, i}\left({ }^{\circ} \mathrm{C}\right)$ & $\dot{m}_{s, i}(\mathrm{~g} / \mathrm{s})$ & $T_{c w, i}\left({ }^{\circ} \mathrm{C}\right)$ & & $P_{s, o}(\mathrm{kPa})$ & $T_{s, o}\left({ }^{\circ} \mathrm{C}\right)$ & $x_{s, o}(\%)$ \\
\hline 30 & 0.1 & 20 & & 0.34 & 27.1 & 58.2 \\
30 & 0.1 & 30 & & 0.52 & 34.0 & 58.8 \\
30 & 0.4 & 20 & & 0.30 & 28.1 & 59.5 \\
40 & 0.1 & 20 & & 0.35 & 27.6 & 58.3 \\
\hline
\end{tabular}




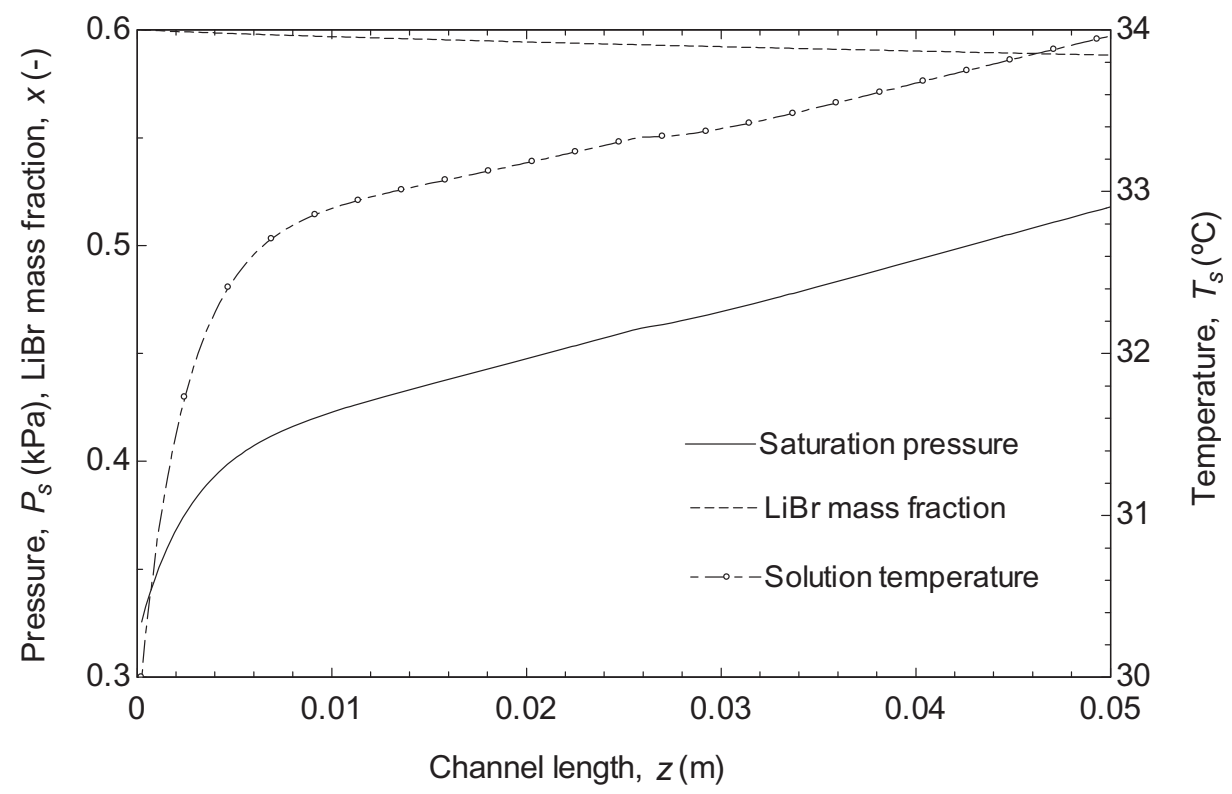

Fig. 6. Evolution of solution temperature, saturation pressure and LiBr mass fraction along the absorption channel.

eters is modified, relative to the result of the base case tabulated in Table 1.

Fig. 7 represents the combined influence of membrane porosity and pore diameter on $r_{q v}$. As it is observed, the higher both variables are, the higher the ratio $r_{q v}$. However, maximum porosity of commercial membranes is around 85\% (Merckmillipore [31]), and maximum pore diameter is limited to avoid aqueous solution penetration into the membrane pores, as discussed by Ali and Schwerdt [5].

The membrane material, characterised by its thermal conductivity, has a negligible influence on the absorber dimensions. The range evaluated in this study, from 0.1 to $0.3 \mathrm{~W} / \mathrm{mK}$, covers typical thermal conductivities of polypropylene (PP), polyvinylidene fluoride (PVDF) and polytetrafluoroethylene (PTFE). These are possible materials to be employed in membrane absorbers (Ali [14]). However, the membrane thickness is a very important parameter, as observed in Fig. 8. When it increases from 50 to $170 \mu \mathrm{m}$, the ratio $r_{q V}$ reduces from 902 to $445 \mathrm{~kW} / \mathrm{m}^{3}$. For this reason, the membrane

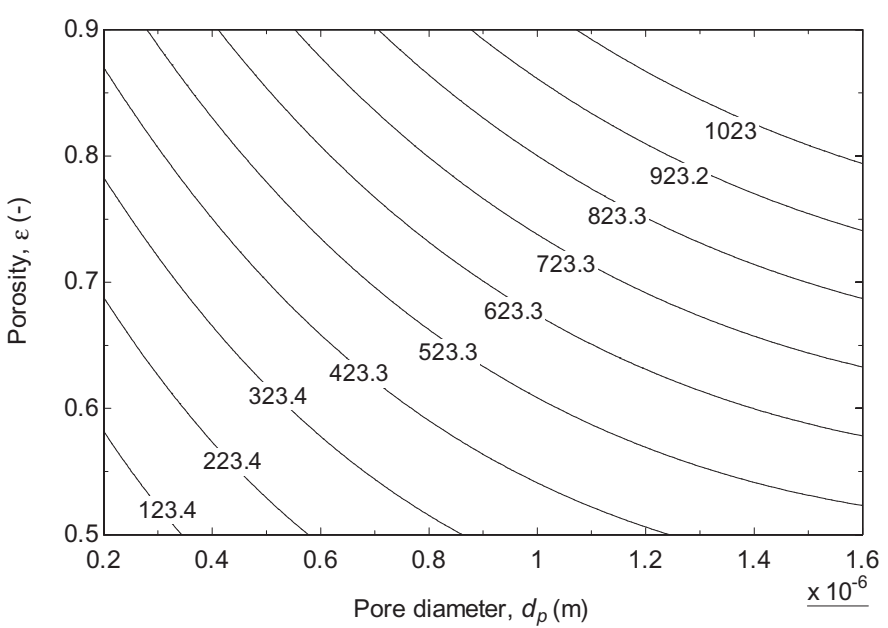

Fig. 7. $r_{q V}$ for different membrane pore diameter $\left(d_{p}\right)$ and porosity $(\varepsilon)$. should be as narrow as possible. Fig. 8 shows also the effect of the solution $\mathrm{LiBr}$ mass fraction at the absorber inlet. Similarly to the membrane thickness, its effect on the chiller dimensions is pronounced. When it is varied from 0.54 to 0.62 , the ratio $r_{q V}$ increases from 302 to $921 \mathrm{~kW} / \mathrm{m}^{3}$.

Fig. 9 shows the influence of cooling water and solution mass flow rates on $r_{q v}$. Solution flow rate has the greatest influence. With respect to the base case, if the total solution flow rate is increased from 0.4 to $1.6 \mathrm{~g} / \mathrm{s}, r_{q V}$ increases from 736 to $891 \mathrm{~kW} / \mathrm{m}^{3}$. However, the same change in the cooling water flow rate only increases the ratio $r_{q V}$ from 826 to $851 \mathrm{~kW} / \mathrm{m}^{3}$. The effect of the vapour mass flow rate on the absorber dimensions is negligible.

The wall properties separating the cooling water and the solution are also important parameters, mainly regarding thickness, as observed in Fig. 10. When it is varied from 0.6 to $3 \mathrm{~mm}$, the ratio $r_{q V}$ decreases from 1128 to $802 \mathrm{~kW} / \mathrm{m}^{3}$. For this reason, special care should be taken to reduce as much as possible the wall thickness. In the present work, the thermal conductivity, varying between 7.5

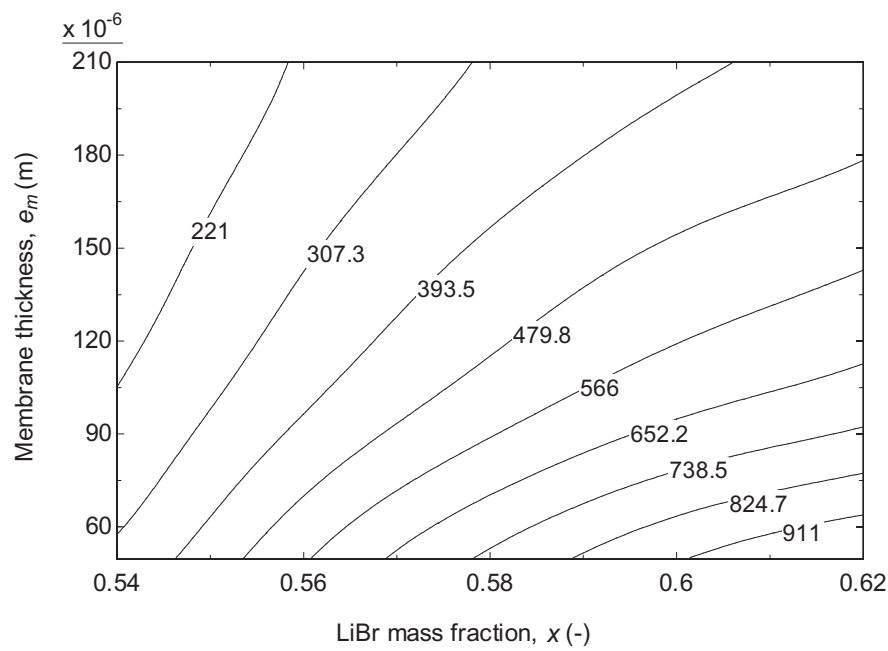

Fig. 8. $r_{q V}$ for different solution inlet concentration $(x)$ and membrane thickness $\left(e_{m}\right)$. 


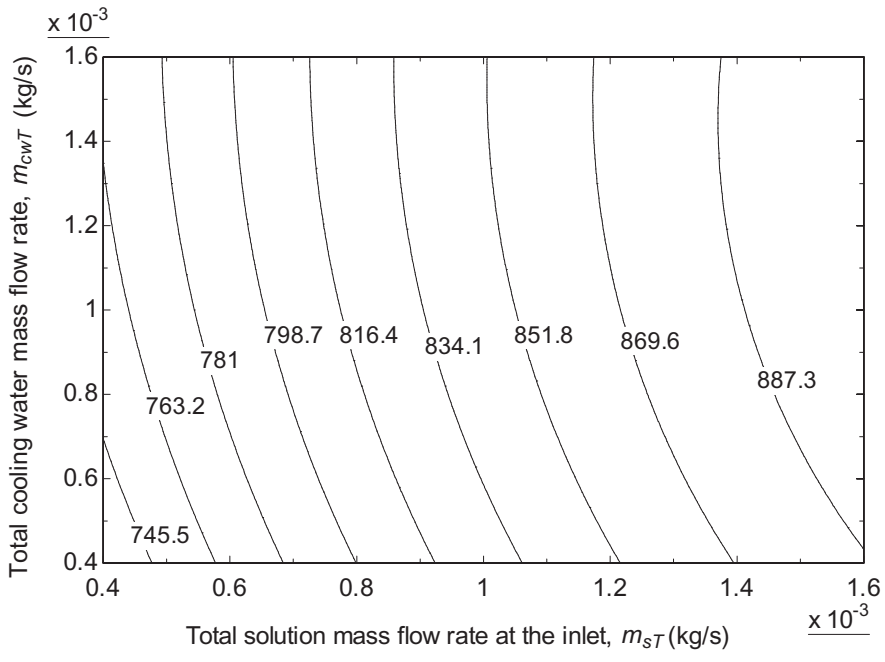

Fig. 9. $r_{q V}$ for different solution and cooling water mass flow rates.

and $25 \mathrm{~W} / \mathrm{mK}$, has a negligible influence on the absorber power density.

Inlet temperatures of the working fluids have shown to be important parameters in the performance of absorbers. As presented in Fig. 11, solution inlet temperature has a strong effect on the absorber compactness. When it is reduced from $50{ }^{\circ} \mathrm{C}$ to $30{ }^{\circ} \mathrm{C}$, the cooling power of the chiller equipped with an absorber of $1 \mathrm{~m}^{3}$ volume increases from 188 to $899 \mathrm{~kW}$, i.e., approximately $35 \mathrm{~kW} /{ }^{\circ} \mathrm{C}$. Regarding the cooling water inlet temperature, its effect is slightly less important. If the inlet temperature decreases in the range from 32 to $20^{\circ} \mathrm{C}$, the corresponding cooling power increases from 755 to $938 \mathrm{~kW}$, i.e., approximately $15 \mathrm{~kW} /{ }^{\circ} \mathrm{C}$.

In absorption chillers, vapour might be superheated at the outlet of the evaporator. The influence of the superheating is analysed in this parametric analysis, and a negligible effect on the cooling power per unit of absorber volume is obtained. For this reason, no special care has to be taken to avoid superheating. The effect of vapour pressure on the ratio $r_{q v}$ is shown in Fig. 12. As observed in the figure, pressure has an important effect on the absorber dimensions. When it is increased from 0.8 to $1.6 \mathrm{kPa}$, the cooling power of the chiller equipped with an absorber of $1 \mathrm{~m}^{3}$ volume increases from 589 to 1540 kW, i.e., approximately 1189 kW/kPa.

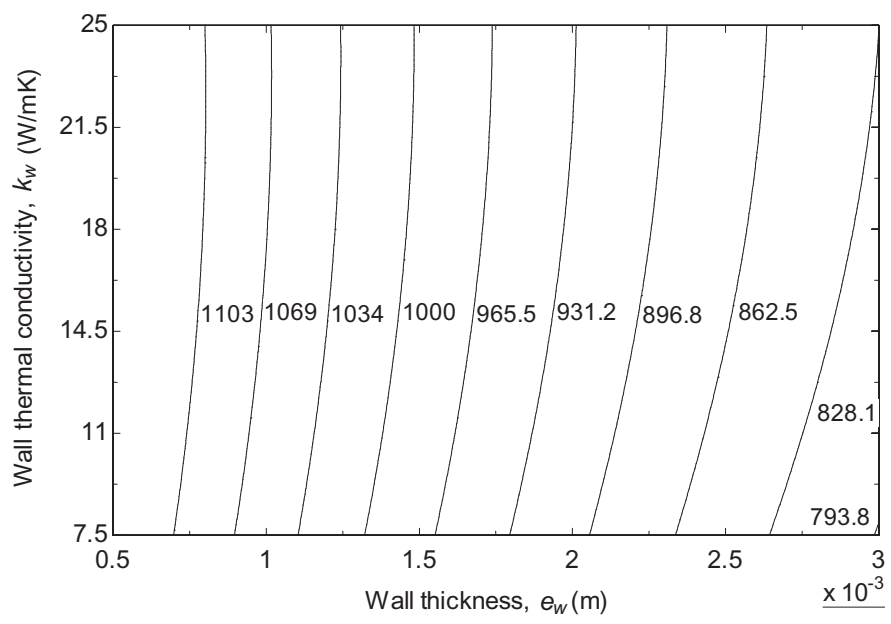

Fig. 10. $r_{q V}$ for different thickness $\left(e_{w}\right)$ and thermal conductivity $\left(k_{w}\right)$ of the metal wall.

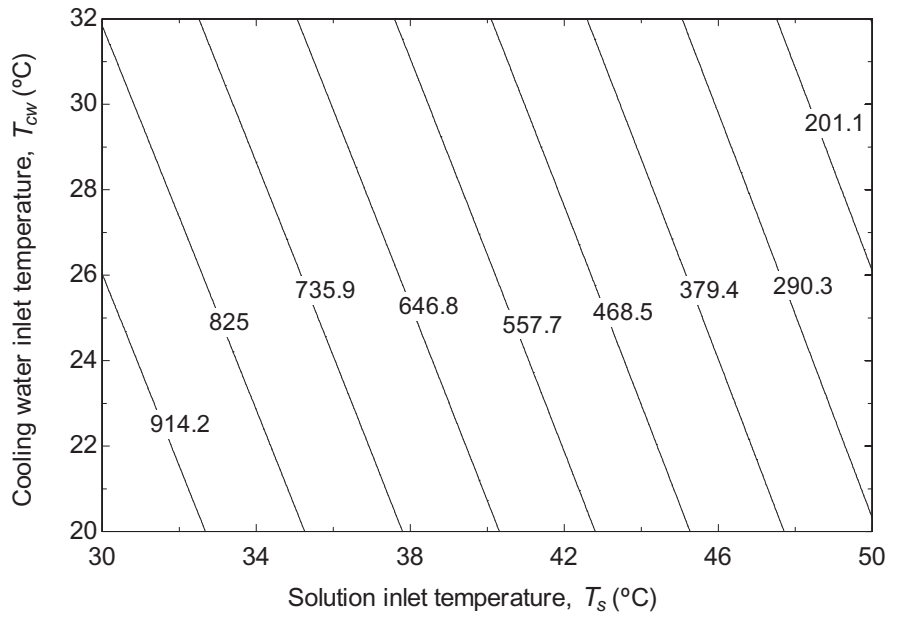

Fig. 11. $r_{q V}$ for different solution $\left(T_{s}\right)$ and cooling water $\left(T_{c w}\right)$ inlet temperatures.

In the parametric analysis, the solution and the cooling water channels width, $l_{s}$ and $l_{c w}$, are modified independently, in the ranges shown in Table 3. The influence of the cooling water channel width on the ratio $r_{q v}$ is negligible. However, there is a noticeable effect of the solution channel width on the ratio $r_{q V}$ as observed in Fig. 12, more pronounced at widths smaller than $0.6 \mathrm{~mm}$. It rises from 567 to $832 \mathrm{~kW} / \mathrm{m}^{3}$ when the width increases from to 0.15 to $1.5 \mathrm{~mm}$.

The height of the solution and the cooling water channels directly affects the dimensions of the chiller. Fig. 13 depicts how the channels height modifies the ratio $r_{q v}$. Once more, it is shown that the parameters associated to the solution have the strongest influence. In this case, when the solution channel height is reduced from 1.5 to $0.15 \mathrm{~mm}$, the ratio $r_{q V}$ increases from 276 to $832 \mathrm{~kW} / \mathrm{m}^{3}$. Small depth channel provides small solution thickness, which reduces the solution mass transfer resistance. As it is also observed, the influence of the solution channel height is more pronounced at smaller sizes. When changing the cooling water channel height, if it is modified in the same range as the solution channel height, the ratio $r_{q V}$ only increases from 688 to $832 \mathrm{~kW} / \mathrm{m}^{3}$.

The relative influence of all the parameters considered in the present work is considered in Fig. 14. The weight of each parameter is represented in terms of the total percentage change produced in the ratio $r_{q v}$, respect to the base case, when the parameter is varied in the range shown in Table 3. The maximum change is obtained

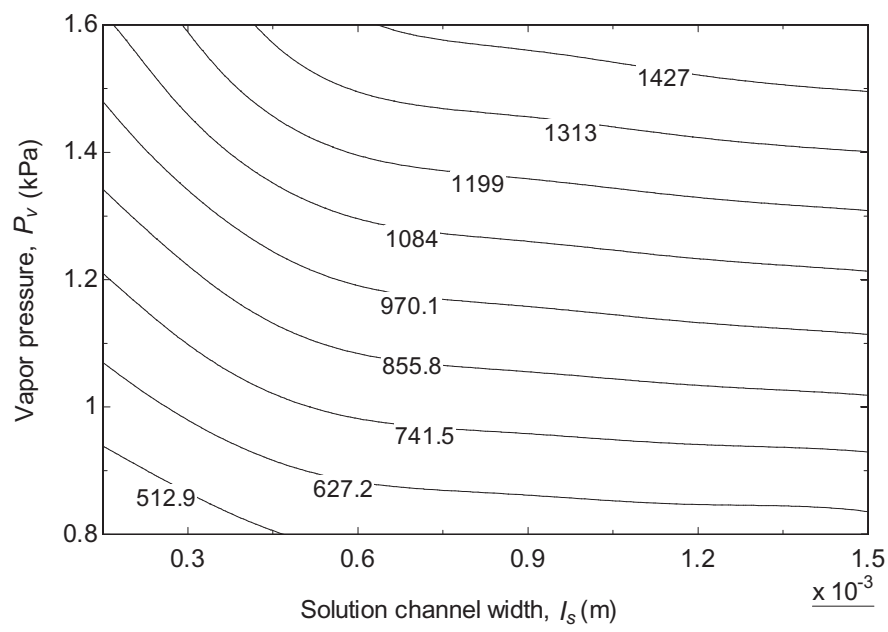

Fig. 12. $r_{q V}$ for different solution channels width $\left(l_{s}\right)$ and vapour pressure $\left(P_{v}\right)$. 


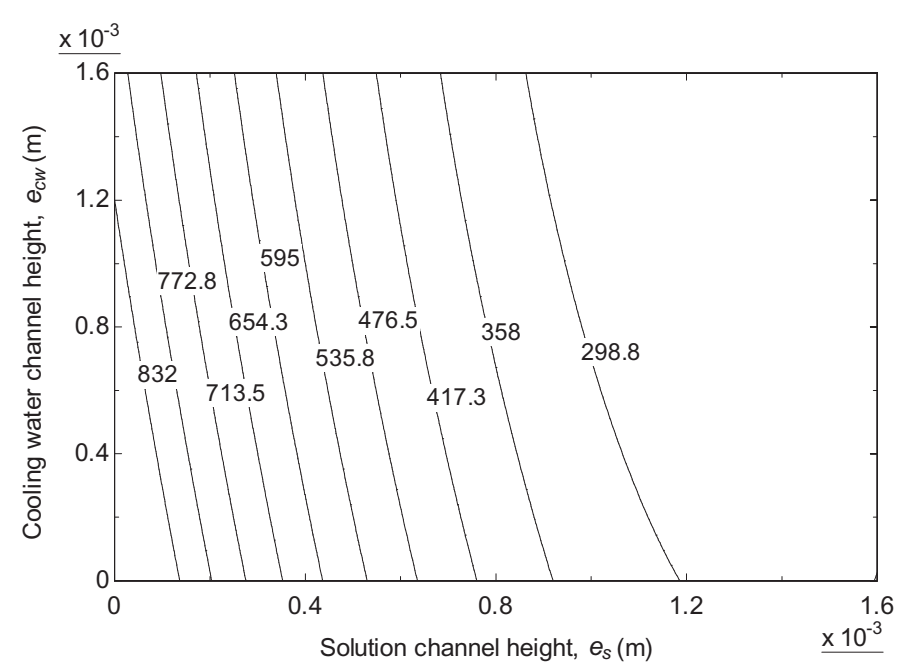

Fig. 13. $r_{q V}$ for different solution $\left(e_{s}\right)$ and cooling water $\left(e_{c w}\right)$ channels height.

when the vapour pressure is modified, showing the sensitivity of the absorber dimensions to the evaporator pressure. In practice, this pressure is limited by the final use of the chiller, the comfort conditions of the conditioned rooms and the type of cool air distribution system. As observed in Table 3, a percentage increase in $r_{q V}$ of near $85 \%$ is obtained if vapour pressure is increased until $1.6 \mathrm{kPa}$. A decrease of about $30 \%$ corresponds to a pressure of $0.8 \mathrm{kPa}$.

The following most important parameters, in order of decreasing importance, are the solution inlet temperature, membrane porosity, solution inlet concentration, membrane pore diameter, depth of the solution channels and membrane thickness. All of them are responsible of total percentage changes higher than $60 \%$ when they are modified in the range given in Table 3. Regarding parameters associated to the absorber operation, the solution inlet temperature and concentration can be optimised. The first one should be lowered as much as possible, using a solution subcooler at the inlet of the absorber, while the second one has to be increased up to the maximum value that prevents from crystallisation. Regarding the design parameters, at the design stage, membrane porosity and pore diameter are recommended to be increased as much as technically possible. The membrane thickness and the solution channel depth should be as thin as possible. The importance

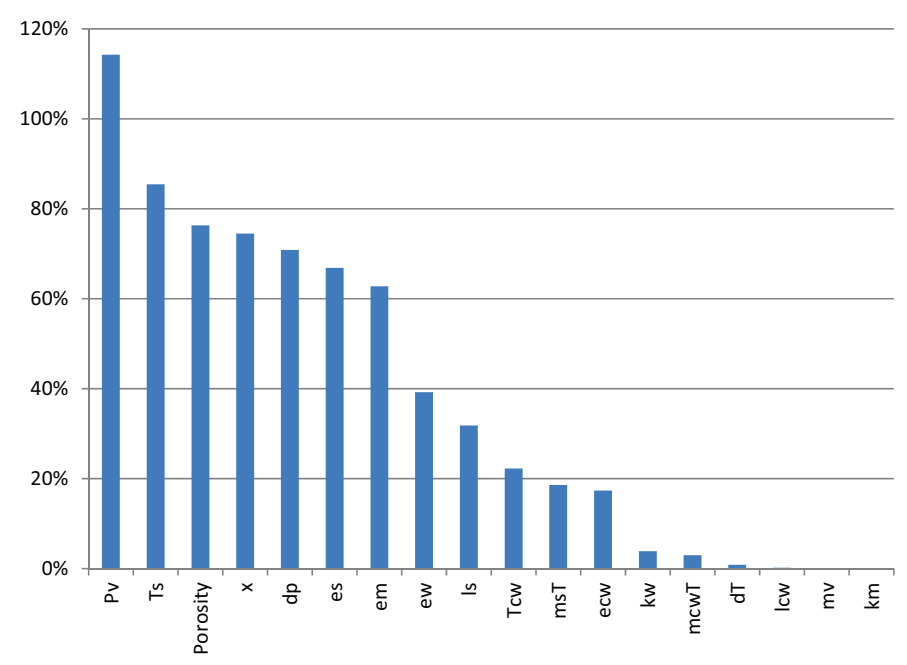

Fig. 14. Percentage influence of the parameters on $r_{q V}$ respect to the base case. of decreasing the solution channel depth was experimentally verified by Isfahani and Moghaddam [7], showing an increment in the absorption rate when the depth was reduced from 160 to $100 \mu \mathrm{m}$.

The thickness of the wall between the solution and the cooling water channels is the next parameter in importance, as represented in Fig. 14. In this case a percentage variation of near $40 \%$ is obtained in $r_{q V}$ if the thickness is modified in the range shown in Table 3. Again, this is a design parameter to be considered at the construction phase. Techniques to reduce as much as possible the wall thickness are recommended to be employed.

Next important parameters, in decreasing order in Fig. 14, are the solution channel width, cooling water inlet temperature, solution mass flow rate and cooling water channel depth. During the operation of the chiller, the cooling water inlet temperature is limited by the recooling systems, so it has to be optimised. Also, the solution mass flow rate should be increased as much as possible. For optimising the design of the absorber, the solution channel width should be as wide as possible and the cooling water channel depth should be as thin as viable.

Finally, design and operating parameters that less influence the absorber performance are: thermal conductivity of the wall, cooling water flow rate, vapour inlet superheating, cooling water channel width, vapour flow rate and thermal conductivity of the membrane. No special efforts have to be taken to optimise these parameters because their change in the ranges given in Table 3 produces a total percentage change of $r_{q V}$ lower than $4 \%$.

It is important to note that values of $r_{q V}$ given in the present work correspond to a simple module, as represented in Fig. 1. If the absorber is constructed forming a parallel system, in such a way that the vapour and cooling water channels are shared by the adjacent modules, the ratio $r_{q V}$ can be increased almost twice.

\section{Conclusions}

In the present paper, a parametric study has been developed to analyse the impact of design and operating conditions on the performance of a miniaturised membrane based-absorber. The aspect ratios evaluated for the solution and the cooling water channels vary between 1 and 10. The ratio between the cooling power of the chiller and the absorber volume is the selected parameter to be maximised. The following conclusions have been derived:

- At the design stage of the membrane absorber, the most relevant parameters in decreasing order of importance are: porosity and pore diameter of the membrane, solution channels depth, thicknesses of the membrane and of the interface wall between the solution and the cooling water, solution channels width and cooling water channels depth. The porosity and pore diameter of the membrane and the solution channel width should be as high as possible. The solution channels depth, the thicknesses of the membrane and of the wall separating the solution and the cooling water and also the cooling water channels depth should be reduced as much as reasonable.

- During operation of the absorber, also in decreasing order of importance, special care should be taken to select the adequate vapour pressure, solution inlet temperature and concentration, cooling water inlet temperature and solution mass flow rate. The vapour pressure, the solution inlet concentration and the solution mass flow rate should be as high as technically viable. The solution and cooling water inlet temperatures should be reduced as much as possible.

- The remain parameters (thermal conductivity of the wall, cooling water flow rate, vapour inlet superheating, cooling water channel width, vapour flow rate and thermal conductivity of the membrane) have a negligible influence on the absorber size optimisation. 


\section{Acknowledgement}

The financial support of this study by the Ministerio de Economía y Competitividad of Spain through the research grant ENE201343131- $\mathrm{R}$ is greatly appreciated.

\section{Nomenclature}

A area $\left(\mathrm{m}^{2}\right)$

$C_{p} \quad$ specific heat $\left(\mathrm{kJ} \mathrm{kg}^{-1} \mathrm{~K}^{-1}\right)$

$D_{h} \quad$ hydraulic diameter $(\mathrm{m})$

$d_{p} \quad$ membrane pore diameter $(\mathrm{m})$

$d z \quad$ discretisation length $(\mathrm{m})$

$e \quad$ height or thickness (m)

$h \quad$ convective heat transfer coefficient $\left(\mathrm{W} \mathrm{m}^{-2} \mathrm{~K}^{-1}\right)$

$i \quad$ specific enthalpy $\left(\mathrm{kJ} \mathrm{kg}^{-1}\right)$

$J \quad$ absorption rate $\left(\mathrm{kg} \mathrm{m}^{-2} \mathrm{~s}^{-1}\right)$

$k$ thermal conductivity $\left(\mathrm{W} \mathrm{K}^{-1} \mathrm{~m}^{-1}\right)$

$K \quad$ mass transfer coefficient $\left(\mathrm{kg} \mathrm{Pa}^{-1} \mathrm{~m}^{-2} \mathrm{~s}^{-1}\right)$

$K n \quad K n u d s e n$ number, $K n=\lambda / d_{p}$

$l \quad$ width $(\mathrm{m})$

$L \quad$ total length of channels (m)

$\dot{m} \quad$ mass flow rate $\left(\mathrm{kg} \mathrm{s}^{-1}\right)$

M molecular weight $\left(\mathrm{kg} \mathrm{mole}^{-1}\right)$

$\mathrm{Nu} \quad$ Nusselt number, $\mathrm{Nu}=h D_{h} / k$

$P \quad$ pressure (Pa)

$\operatorname{Pr} \quad$ Prandtl number, $\operatorname{Pr}=\mu C_{p} / k$

$q \quad$ thermal power (W)

$R \quad$ mass transfer resistance $\left(\mathrm{kg}^{-1} \mathrm{~Pa} \mathrm{~m} \mathrm{~m}^{2} \mathrm{~s}\right)$

Re Reynolds number, $\operatorname{Re}=u D_{h} \rho / \mu$

$r_{q V} \quad$ ratio between the cooling power and the absorber volume $\left(\mathrm{kW} \mathrm{m}^{-3}\right)$

$R_{u} \quad$ universal gases constant $\left(\mathrm{J} \mathrm{mole}^{-1} \mathrm{~K}^{-1}\right)$

$T$ temperature $\left({ }^{\circ} \mathrm{C}\right)$

$u \quad$ velocity $\left(\mathrm{m} \mathrm{s}^{-1}\right)$

$U \quad$ global heat transfer coefficient $\left(\mathrm{W} \mathrm{m}^{-2} \mathrm{~K}^{-1}\right)$

$V \quad$ volume $\left(\mathrm{m}^{3}\right)$

$x \quad$ lithium bromide mass fraction $\left(\mathrm{kg}_{\mathrm{LiBr}} \mathrm{kg}_{\mathrm{s}}{ }^{-1}\right)$

$z \quad$ axial coordinate $(\mathrm{m})$

$z^{*} \quad$ dimensionless axial distance, $z^{*}=z /\left(\operatorname{Re} \operatorname{Pr} D_{h}\right)$

\section{Greek symbols}

$\alpha \quad$ channel aspect ratio (always $\geq 1$ ), $\alpha=l / e$.

$\beta \quad$ reduced thermal polarisability

$\Delta T \quad$ vapour inlet superheating $\left({ }^{\circ} \mathrm{C}\right)$

$\varepsilon \quad$ porosity (-)

$\varphi \quad$ fractional volume of the solid material

$\lambda \quad$ mean free path $(\mathrm{m})$

$\mu \quad$ viscosity (Pa s)

$\Xi \quad$ Ackermann factor

$\rho \quad$ density $\left(\mathrm{kg} \mathrm{m}^{-3}\right)$

$\tau \quad$ tortuosity

$\Phi \quad$ heat transfer rate factor

\section{Subscripts}

a absorber

cw cooling water

e evaporator

$g \quad$ generator

$i \quad$ inlet

$K \quad$ Knudsen

lv liquid-vapour

$m$ membrane

o outlet

ov overall

$P \quad$ Poiseuille

$\begin{array}{ll}s & \text { solution } \\ \text { sat } & \text { saturation } \\ T & \text { total } \\ t h & \text { thermal } \\ v & \text { vapour } \\ v a & \text { vapour absorbed } \\ w & \text { wall }\end{array}$

\section{References}

[1] N. García-Hernando, J.A. Almendros-Ibañez, G. Ruiz, M. de Vega, On the pressure drop in Plate Heat Exchangers used as desorbers in absorption chillers, Energy Convers. Manage. 52 (2011) 1520-1525.

[2] M. Venegas, D. Arzoz, P. Rodríguez, M. Izquierdo, Heat and mass transfer in LiNO3-NH3 spray absorption system, Int. Commun. Heat Mass Transf. 30 (2003) 805-815.

[3] M. de Vega, J.A. Almendros-Ibañez, G. Ruiz, Performance of a LiBr-water absorption chiller operating with plate heat exchangers, Energy Convers. Manage. 47 (2006) 3393-3407.

[4] A.H.H. Ali, P. Schwerdt, Characteristics of the membrane utilized in a compact absorber for lithium bromide-water absorption chillers, Proc 9th Int IEA Heat Pump Conf, Switzerland, Paper ID 5.51, 2008.

[5] A.H.H. Ali, P. Schwerdt, Characteristics of the membrane utilized in a compact absorber for lithium bromide-water absorption chillers, Int. J. Refrig. 32 (2009) 1886-1896.

[6] A.H.H. Ali, P. Schwerdt, For designing a compact absorber with membrane contactor at liquid-vapor interface: influence of membrane properties on water vapour transfer, ASHRAE Trans. 116 (2010) 398-407.

[7] R.N. Isfahani, S. Moghaddam, Absorption characteristics of lithium bromide (LiBr) solution constrained by superhydrophobic nanofibrous structures, Int. J. Heat Mass Transf. 63 (2013) 82-90.

[8] R.N. Isfahani, K. Sampath, S. Moghaddam, Nanofibrous membrane-based absorption refrigeration system, Int. J. Refrig. 36 (2013) 2297-2307.

[9] D. Yu, J. Chung, S. Moghaddam, Parametric study of water vapour absorption into a constrained thin film of lithium bromide solution, Int. J. Heat Mass Transf. 55 (2012) 5687-5695.

[10] S. Bigham, D. Yu, D. Chugh, S. Moghaddam, Moving beyond the limits of mass transport in liquid absorbent microfilms through the implementation of surface-induced vortices, Energy 65 (2014) 621-630.

[11] F. Asfand, M. Bourouis, A review of membrane contactors applied in absorption refrigeration systems, Renew. Sustain. Energy Rev. 45 (2015) 173-191.

[12] M. Venegas, M. de Vega, N. García-Hernando, U. Ruiz-Rivas, A simple model to predict the performance of a $\mathrm{H}_{2} \mathrm{O}-\mathrm{LiBr}$ absorber operating with a microporous membrane, Energy (2016) doi:10.1016/j.energy.2015.12.059 (revised version of the manuscript submitted to the journal).

[13] E.A. Mason, A.P. Malinauskas, Gas Transport in Porous Media: The Dusty-Gas Model, Elsevier, New York, 1983.

[14] A.H.H. Ali, Design of a compact absorber with a hydrophobic membrane contactor at the liquid-vapor interface for lithium bromide-water absorption chillers, Appl. Energy 87 (2010) 1112-1121.

[15] S.B. Iversen, V.K. Bhatia, K. Dam-Johansen, G. Jonsson, Characterization of microporous membranes for use in membrane contactors, J. Membr. Sci. 130 (1997) 205-217.

[16] P.-S. Lee, S.V. Garimella, Thermally developing flow and heat transfer in rectangular microchannels of different aspect ratios, Int. J. Heat Mass Transf. 49 (2006) 3060-3067.

[17] R.K. Shah, A.L. London, Laminar flow forced convection in ducts, in: Laminar Flow Forced Convection in Ducts: A Source Book for Compact Heat Exchanger Analytical Data, Advances in Heat Transfer, Academic Press, New York, 1978. Suppl. 1.

[18] L. Martínez, J.M. Rodríguez-Maroto, Characterization of membrane distillation modules and analysis of mass flux enhancement by channel spacers, J. Membr. Sci. 274 (2006) 123-137.

[19] M.C. García-Payo, M.A. Izquierdo-Gil, Thermal resistance technique for measuring the thermal conductivity of thin microporous membranes, J. Phys. D Appl. Phys. 37 (2004) 3008-3016.

[20] R. Taylor, R. Krishna, Multicomponent Mass Transfer, John Wiley \& Sons, New York, 1993.

[21] S.A. Klein, Engineering Equation Solver. Academic Professional, 1992-2014, V9.698-3D, 2014.

[22] J. Patek, J. Klomfar, A computationally effective formulation of the thermodynamic properties of $\mathrm{LiBr}-\mathrm{H}_{2} \mathrm{O}$ from 273 to $500 \mathrm{~K}$ over full composition range, Int. J. Refrig. 29 (2006) 566-578.

[23] L. Harr, J.S. Gallagher, G.S. Kell, NBS/NRC Steam Tables, Hemisphere Publishing Co, New York, 1984.

[24] R.J. Lee, R.M. DiGuilio, S.M. Jeter, A.S. Teja, Properties of lithium bromide-water solutions at high temperatures and concentrations - II density and viscosity, ASHRAE Trans. RP-527 (1990) 709-714.

[25] R.M. DiGuilio, R.J. Lee, S.M. Jeter, A.S. Teja, Properties of lithium bromide-water solutions at high temperatures and concentrations - I thermal conductivity, ASHRAE Trans. RP-527 (1990) 702-708. 
[26] Electrical Research Association Steam Tables, Thermodynamic Properties of Water and Steam; Viscosity of Water and Steam, Thermal Conductivity of Water and Steam, Edward Arnold Publishers, London, 1967.

[27] M.L. Huber, R.A. Perkins, D.G. Friend, J.V. Sengers, M.J. Assael, I.N. Metaxa, et al., New international formulation for the thermal conductivity of $\mathrm{H}_{2} \mathrm{O}$, J. Phys. Chem. Ref. Data 41 (2012) 033102-1-23.

[28] M.L. Huber, R.A. Perkins, A. Laesecke, D.G. Friend, J.V. Sengers, M.J. Assael, et al., New international formulation for the viscosity of $\mathrm{H}_{2} \mathrm{O}$, J. Phys. Chem. Ref. Data 38 (2009) 101-125.
[29] M. Mittermaier, P. Schulze, F. Ziegler, A numerical model for combined heat and mass transfer in a laminar liquid falling film with simplified hydrodynamics, Int. J. Heat Mass Transf. 70 (2014) 990-1002.

[30] S.L. Chawla, R.K. Gupta, Materials Selection for Corrosion Control, ASM International, Materials Park, OH, 1993.

[31] Merckmillipore, Product catalogue. <www.merckmillipore.com>, 2015 (accessed 01.10.15). 